\title{
Prevalence of Tea Consumption among University Students of South-Eastern Region of Bangladesh and Associated Factors
}

\author{
${\text { Jakia Sultana Jothi }{ }^{1, a, *} \text {, Nahidur Rahman }}^{1, \mathrm{~b}}$, Anindya Chakraborty ${ }^{1, \mathrm{c}}$, Shireen Akther ${ }^{1, \mathrm{~d}}$ \\ ${ }^{I}$ Department of Food Processing and Engineering, Faculty of Food Science and Technology, Chattogram Veterinary and Animal Sciences \\ University, Khulshi, 4225 Chattogram, Bangladesh \\ ${ }^{*}$ Corresponding author

A R T I C L E I N O A B S T R A C T \\ Research Article \\ Tea has become an integral part of our culture and everyday life due to taste, together with a \\ refreshing and mildly stimulant effect. The study was carried out to investigate the behaviour pattern \\ and prevalence observed due to regular consumption of tea as a source of caffeine among the \\ university students using a self-reported validated questionnaire. Socio-demographic and data \\ related to tea consumption pattern were collected and analysed statistically. Among 245 study \\ participants, the majority chose a greater proportion of tea $(83.7 \%)$ followed by coffee $(14.7 \%)$. \\ The main reasons for tea consumption by university students included keeping alert during the \\ examination period $(38.8 \%$ ), followed by the removal of anxiety and stress. Students (around 61\%) \\ mostly consume $2-3$ cup of tea per day. According to the study, $12.7 \%$ of students had never \\ consumed tea. More than two-thirds $(66.9 \%)$ of the students reported having a sound sleep, normal \\ Keywords: \\ BMI and blood pressure, a majority of them were engaged with regular physical exercise. The study \\ Tea \\ also illustrated that most of the students $(52.7 \%)$ give priority to the quality of the product rather \\ than price, brand and taste while buying packaged tea leaves. Thus, this study provides basics about \\ Caffeine \\ Consumption pattern \\ Associated factors \\ University students \\ the prevalence and presents a recommendation for expanding tea consumption market among the \\ university students.
}

\section{Introduction}

Tea represents one of the important agricultural products in Bangladesh, with a total production of 82.13 million Kilogram $(\mathrm{kg})$ in 2018, as estimated by the Bangladesh Tea Board (The Daily Star, 2019). It is the most widely consumed beverage after water (Chatterjee et al., 2012). The evergreen tea plant (Camellia sinensis), is valued for its young leaves and buds, which are used to produce the beverage. Tea can be differentiated based on their manufacturing process, for example, 'non-fermented' green tea, 'semi-fermented' oolong tea, and 'fermented' black tea (Subramaniam et al., 2012). Tea has been proven to express a cardio-protective and lipid-lowering effect (Vartanian et al., 2007). Polyphenols are the primary chemical components and flavonoids, which are the main polyphenols present in tea, have been elucidated to be related to vascular health (Hodgson and Croft, 2010).

Habitual tea consumption is a very common scenario in Bangladesh. People start their day with hot tea sips. University students usually exposed to stresses due to their academic load (Bjorksten et al., 1983). As a result of their overwhelming, stressful situations, students tend to cope with consuming caffeinated beverages, mostly teas. Teas usually contain $3 \%$ caffeine (dry weight), translating to between $30 \mathrm{mg}$ and $90 \mathrm{mg}$ per 8-oz (250-ml) cup depending on type, brand and brewing method (Hicks et al., 1996). It is a natural chemical which activates our central nervous system. Apart from this, caffeine is considered to be an addictive drug,_and high caffeine consumption is known to have adverse effects, including an increase in blood pressure and sleep disturbances in adolescents. Besides habitual tea consumption is associated with a lower waist/hip ratio and a lower BMI in adults (Wu et al., 2003). However, caution is advised against the consumption of high levels of caffeine in any form (Arria et al., 2014).

Despite the rising trends and marketing strategies aimed toward university students, there has been little research done on university students' intake of tea and relevant facts. As per the review literature, no studies have been carried out 
yet in Bangladesh; regarding the prevalence of tea consumption among the university students. Thus, the study aims to investigate the patterns and motivations of tea consumption and its associated factors among the university students of the south-eastern region of Bangladesh.

\section{Methodology}

\section{Study Setting and Sample}

A cross-sectional study was conducted among the students from five different universities of Chattogram, situated in the south-eastern region of Bangladesh. A simple random sampling technique was used for the selection of study participants. The sample size was calculated via total population estimated as 2000 with $5 \%$ margin of error and $90 \%$ confidence level. Thus, the sample size was calculated to be 239 . However, to ensure more representative data, a total of 245 students (45-50 from each of the university) were participated in the study. Data were assembled by a self-administered questionnaire. Pre-testing of the initial questionnaire was done among 20 students who were randomly selected and not included in the final data. Necessary corrections and modifications were done upon the responses from field-testing. Informed consents were obtained prior to data collection. All study questionnaires were anonymous, and no personal identifiers were collected.

\section{Assessment of Baseline Characteristics}

Socio-demographic profile including gender, discipline, academic year, a field of study and institutions were self-reported. The questionnaire also contained some other information's like BMI, blood pressure, frequency of physical exercise, sleep quality to assess the baseline characteristics of the study participants.

\section{Tea Consumption Assessment}

The questionnaire contained some open-ended questions regarding knowledge and perceptions of students about tea consumption, product type, preferences of using sugar and milk while consuming tea. Students were also asked multi-response questions regarding situations and purposes in which they consume tea, how often they consume tea. Tea consumers were also asked about the preference of tea type.

\section{Statistical Analysis}

Data obtained were analyzed by using the statistical package SPSS (version 23.0) software. The results of the descriptive analysis were represented as frequencies and percentages (pie charts and graphical representation) in the case of qualitative variables. A confidence level of $95 \%$ $(\mathrm{P}<0.05)$ was accepted for all statistical analysis.

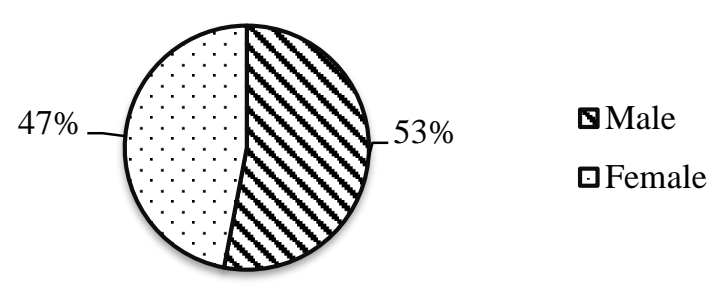

Figure 1. Ratio of the study participants

\section{Result}

\section{Baseline Characteristics of the Study Participants}

Out of 245 study participants, 130 were male (24 of them are post graduate and 106 are undergraduate students) and 115 were female ( 20 of them are post graduate and 95 are undergraduate students). So, the ratio of the study participants (male-female) was 53\%-47\% (Figure 1).

Table 1 represents the baseline characteristics of the students who participated in the present study. About twothirds $(66.9 \%)$ of the study participants reported having normal BMI, while $11.8 \%$ and $13.1 \%$ of the participants were reported underweight and overweight respectively. Rests of the students $(8.2 \%)$ were found to have some degree of obesity. Table 1 illustrate the prevalence of blood pressure (bp) where a majority of students (85.7\%) reported to have normal bp, whereas only $9.4 \%$ and $4.9 \%$ students have some fluctuation in blood pressure ranging from low to high respectively, consequently $29.4 \%$ students were found to have abdominal fat and the rest $70.6 \%$ students had to lack abdominal fat. Approximately one-third $(31.4 \%)$ of the study participants reported engaging in 1-2 hours exercise per day while $44.5 \%$ of the study participants reported no exercise at all. $3.3 \%$ of the participants reported that they were engaged to some type of physical activity (less than 1 hour), whereas $20.8 \%$ of the participants were highlighted with more than 3 hours regular exercise per day. Table 1 also demonstrated the result of sleep quality among the study participants. More than two-thirds $(81.6 \%)$ of the participants reported having a sound sleep, while $18.4 \%$ of students found to have some sort of disturbance during sleeping.

\section{Tea Consumption Pattern}

Table 2 demonstrates the frequency of tea consumed and behavioural factors related to its consumption among the study participants. According to the beverage type, students chose a greater proportion of tea $(83.7 \%)$ followed by coffee $(14.7 \%)$ and in smaller proportion $(1.6 \%)$ consume both tea and coffee. Approximately more than one-third of the study participants $(38.8 \%)$ reported that they consume a greater amount of tea during the examination period. Some other reported causes were to release stress $(31.3 \%)$, to keep them awake during both examination time and stress condition $(19.2 \%)$ and for keeping refreshed $(10.6 \%)$.

Approximately more than one-third of the students $(39.6 \%)$ consume at least 2 cups of teas per day, and $21.6 \%$ of the students consume more than 3 cups per day while $26.1 \%$ drink only a cup. Around $12.7 \%$ of the participants responded 'no' when asked whether they consumed it daily. In comparison with weekly consumption pattern, Table 2 illustrated that majority of the study participants (49.8\%) consume 3-6 cup of teas per week whereas $40.4 \%$ of the students consume 10-14 cups. Approximately $8.2 \%$ of the students consume at most numbers that are more than 14 cups per week while only $1.6 \%$ of students were reported that they do not consume tea at all.

Regarding students' knowledge and attitude towards consumption of tea, more than three-quarter of the study participants were found to prefer black tea $(82.4 \%)$ rather than green tea $(9.8 \%)$, organic tea $(1.2 \%)$ and others $(6.6 \%)$. 
Table 1. Baseline characteristics of the study participants $(n=245)$

\begin{tabular}{|c|c|c|c|c|}
\hline Variable & Male $(n=130)$ & Female $(n=115)$ & Total $(n=245)$ & Percent \\
\hline \multicolumn{5}{|c|}{ Graduation status } \\
\hline Post Graduate & $24(18.5 \%)$ & $20(17.4 \%)$ & 44 & $18 \%$ \\
\hline Under Graduate & $106(81.5 \%)$ & $95(82.6 \%)$ & 201 & $82 \%$ \\
\hline \multicolumn{5}{|c|}{ BMI } \\
\hline Under weight & $13(10 \%)$ & $16(13.9 \%)$ & 29 & $11.8 \%$ \\
\hline Normal & $88(67.7 \%)$ & $76(66.1 \%)$ & 164 & $66.9 \%$ \\
\hline Over weight & $19(14.6 \%)$ & $13(11.3 \%)$ & 32 & $13.1 \%$ \\
\hline Obese & $10(7.7 \%)$ & $10(8.7 \%)$ & 20 & $8.2 \%$ \\
\hline \multicolumn{5}{|c|}{ Blood Pressure (bp) } \\
\hline Low & $2(1.5 \%)$ & $21(18.3 \%)$ & 23 & $9.4 \%$ \\
\hline Normal & $124(95.4 \%)$ & $86(74.7 \%)$ & 210 & $85.7 \%$ \\
\hline High & $4(3.1 \%)$ & $8(7.0 \%)$ & 12 & $4.9 \%$ \\
\hline \multicolumn{5}{|c|}{ Abdominal Fat } \\
\hline Present & $32(24.6 \%)$ & $40(34.8 \%)$ & 72 & $29.4 \%$ \\
\hline Absent & $98(75.4 \%)$ & $75(65.2 \%)$ & 173 & $70.6 \%$ \\
\hline \multicolumn{5}{|c|}{ Regular Exercise } \\
\hline No exercise & $46(35.4 \%)$ & $63(54.8 \%)$ & 109 & $44.5 \%$ \\
\hline$<1 \mathrm{hr}$. exercise & $3(2.3 \%)$ & $5(4.4 \%)$ & 8 & $3.3 \%$ \\
\hline 1-2 hr. exercise & $49(37.7 \%)$ & $28(24.3 \%)$ & 77 & $31.4 \%$ \\
\hline 3 or more hr. & $32(24.6 \%)$ & $19(16.5 \%)$ & 51 & $20.8 \%$ \\
\hline \multicolumn{5}{|c|}{ Sleep Quality } \\
\hline Good & $107(82.3 \%)$ & $93(80.9 \%)$ & 200 & $81.6 \%$ \\
\hline Poor & $23(17.7 \%)$ & $22(19.1 \%)$ & 45 & $18.4 \%$ \\
\hline
\end{tabular}

Table 2. Tea consumption pattern

\begin{tabular}{|c|c|c|c|c|}
\hline Variables & Male $(n=130)$ & Female $(n=115)$ & Total $(n=245)$ & Percent \\
\hline \multicolumn{5}{|c|}{ Beverage Type } \\
\hline Tea & $115(88.5 \%)$ & $90(78.3 \%)$ & 205 & $83.7 \%$ \\
\hline Coffee & $13(10 \%)$ & $23(20 \%)$ & 36 & $14.7 \%$ \\
\hline Others/Both & $2(1.5 \%)$ & $2(1.7 \%)$ & 4 & $1.6 \%$ \\
\hline \multicolumn{5}{|c|}{ Daily Consumption } \\
\hline Don't drink & $14(10.8 \%)$ & $17(14.8 \%)$ & 31 & $12.7 \%$ \\
\hline 1 cup & $35(27 \%)$ & $29(25.2 \%)$ & 64 & $26.1 \%$ \\
\hline 2 cup & $52(40 \%)$ & $45(39.1 \%)$ & 97 & $39.6 \%$ \\
\hline 3 or more cup & $29(22.2 \%)$ & $24(20.9 \%)$ & 53 & $21.6 \%$ \\
\hline \multicolumn{5}{|c|}{ Weekly Consumption } \\
\hline Don't drink & $2(1.5 \%)$ & $2(1.7 \%)$ & 4 & $1.6 \%$ \\
\hline 3-6 cup & $64(49.2 \%)$ & $58(50.4 \%)$ & 122 & $49.8 \%$ \\
\hline $10-14$ cup & $54(41.5 \%)$ & $45(39.2 \%)$ & 99 & $40.4 \%$ \\
\hline 14 or more cup & $10(7.8 \%)$ & $10(8.7 \%)$ & 20 & $8.2 \%$ \\
\hline \multicolumn{5}{|c|}{ When Consume } \\
\hline Stressed Condition & $48(36.9 \%)$ & $29(25.2 \%)$ & 77 & $31.4 \%$ \\
\hline Examination Time & $42(32.3 \%)$ & $53(46.1 \%)$ & 95 & $38.8 \%$ \\
\hline Both & $26(20 \%)$ & $21(18.3 \%)$ & 47 & $19.2 \%$ \\
\hline Normal Condition & $14(10.8 \%)$ & $12(10.4 \%)$ & 26 & $10.6 \%$ \\
\hline \multicolumn{5}{|c|}{ Type of Tea Consumed } \\
\hline Black Tea & $112(86.1 \%)$ & $90(78.3 \%)$ & 202 & $82.4 \%$ \\
\hline Green Tea & $11(8.5 \%)$ & $13(11.3 \%)$ & 24 & $9.8 \%$ \\
\hline Organic Tea & $2(1.5 \%)$ & $1(0.9 \%)$ & 3 & $1.2 \%$ \\
\hline Others & $5(3.9 \%)$ & $11(9.5 \%)$ & 16 & $6.6 \%$ \\
\hline \multicolumn{5}{|c|}{ Leaf Type } \\
\hline Package Leaf & $67(51.5 \%)$ & $90(78.3 \%)$ & 157 & $64.1 \%$ \\
\hline Tea Bag & $63(48.5 \%)$ & $25(21.7 \%)$ & 88 & $35.9 \%$ \\
\hline \multicolumn{5}{|c|}{ Buying Parameter } \\
\hline Quality & $78(60 \%)$ & $51(44.3 \%)$ & 129 & $52.7 \%$ \\
\hline Taste & $29(22.2 \%)$ & $28(24.3 \%)$ & 57 & $23.3 \%$ \\
\hline Price & $9(7 \%)$ & $24(21 \%)$ & 33 & $13.5 \%$ \\
\hline Brand & $14(10.8 \%)$ & $12(10.4 \%)$ & 26 & $10.5 \%$ \\
\hline \multicolumn{5}{|c|}{ Milk addition with Tea } \\
\hline Yes & $88(67.7 \%)$ & $96(83.5 \%)$ & 184 & $75.1 \%$ \\
\hline No & $37(28.5 \%)$ & $14(12.2 \%)$ & 51 & $20.8 \%$ \\
\hline Sometimes & $5(3.8 \%)$ & $5(4.3 \%)$ & 10 & $4.1 \%$ \\
\hline \multicolumn{5}{|c|}{ Sugar addition with Tea } \\
\hline Yes & $115(88.5 \%)$ & $90(78.3 \%)$ & 205 & $83.7 \%$ \\
\hline No & $11(8.5 \%)$ & $20(17.4 \%)$ & 31 & $12.7 \%$ \\
\hline Sometimes & $4(3 \%)$ & $5(4.3 \%)$ & 9 & $3.6 \%$ \\
\hline
\end{tabular}


Besides almost two-third $(64.1 \%)$ of the study participants reported that they prefer packaged tea leaves whereas $35.9 \%$ reported preferring tea bag. While buying tea leaves/tea-bag, the respondents reported giving top most priority to quality $(52.7 \%)$ followed by taste $(23.3 \%)$, brand $(13.5 \%)$ and price $(10.5 \%)$. Table 2 also illustrated the percentage of respondents who prefers adding milk and sugar while consuming tea. The majority of the participants reported adding milk $(75.1 \%)$ and sugar $(83.7 \%)$ while consuming tea. Other $20.85 \%$ and $12.7 \%$ of the participants highlighted that they neither add milk nor sugar. Rest of the participants reported that they add milk and sugar occasionally.

\section{Discussion}

The study was carried out to observe the prevalence and pattern of tea consumption along with the associated factors among the university students, a high prevalence of tea consumption $(83.7 \%$ ) was observed. In previous studies, the prevalence ranged in between $35-70 \%$ of the consumption of beverages and energy drinks including tea, coffee depending on the places of the study conducted (Majori et al., 2018; Martins et al., 2018). The present study highlighted that $38.8 \%$ of university students consume tea prior to the examination, followed by a stressed condition. The result is in lined with the findings published by Majori et al. (2018) and Champlin et al. (2016). They described energy drinks including tea as the first choice for students to increase concentration and feel less tired during the examination period which is the positive association. In terms of quantity, the present study illustrated that most of the students take two cup of teas per day and 3-6 cups per week. Regarding dependence related to tea, this result is supported by the result published by Naveed and Hameed (2014). Sociodemographic and psychological factors influence the consumers in the selection of tea type. According to Xiong et al. (2015), black tea provides impressive health benefits ranging from lowering the risk of cardiovascular disease to boost immunity. In another study, an independent association between perceived mental stress and green tea consumption was described by Shimbo et al., (2005). Thus, the present study has shown that the majority of the study participants prefer black tea followed by green tea. Inadequate sleep significantly affects the overall well-being of an individual and is associated with a host of unfavourable consequences. High consumption of caffeinated beverages has been suggested as a factor that contributes negatively to sleep quality (McIlvain et al., 2011). But the present study has shown that the majority of the study participants own sound sleep; this might be due to their regular engagement in physical activity. The previous study described that hot tea consumption was inversely associated with obesity: tea consumers had lower mean waist circumference and lowered BMI (25 vs $28 \mathrm{~kg} / \mathrm{m}^{2}$-in male; 26 vs $29 \mathrm{~kg} / \mathrm{m}^{2}$-in the female; both $\mathrm{P}<0.001$ ), than non-consumers (Lambert and Vernarelli, 2013). The result of the present study also in lined with the previously published result. In the present study, we have evaluated the regularity of blood pressure among university students. The obtained result is supported by the study conducted by Nowak et al. (2018) that confirmed that caffeine upsurges systolic blood pressure to $17 \%$ and mean arterial blood pressure to $11 \%$. Previously a study was conducted on the consumption of caffeinated beverages among students of junior and senior high schools in Poland. The study reported that young people select particular energy drinks looking at the taste, price and effect (Nowak and Jasionowski, 2015). The present study showed a similar result as well. Another study conducted in Dhaka, Bangladesh summarized that the prevalence of sugarsweetened beverages like sports/energy drinks, coffee/tea products, and flavoured milk is gaining popularity among adults. Most of the university students (95.4\%) reported consuming sugared beverage stated by Bipasha et al. (2017). The current study has shown similar frequencies of sugar and milk added with tea while consuming. That means trends have been shifted to young people from conventional tea consumption to the tea mixed with sugar syrup, milk, coffee or other fruit essences.

\section{Conclusion}

So far, the results obtained, we may conclude that majority of the university students consume a stimulant drink (tea followed by coffee) and most of them usually consume it during exam periods. The results obtained from the current study contribute to continuing investigating, on relevant factors associated with tea consumption. Suggestions for further studies include assessing whether students have any knowledge of the active ingredients present in tea and whether they have the right information about the potential positive and negative effects of high consumption of caffeinated beverages.

\section{Acknowledgement}

The authors would like to express their gratitude to the Ministry of National Science and Technology, Bangladesh for funding this study. The authors would also like to acknowledge the students of different universities of Chattogram City, Bangladesh who spontaneously participated in this study. Also, we would like to thank all the participants for their support and cooperation throughout data collection.

\section{Conflict of interest}

None to declare.

\section{References}

Arria AM, Bugbee BA, Caldeira KM, Vincent KB. 2014. Energy drink use and high-risk behaviors: Research evidence and knowledge gaps. Nutrition reviews, 72(1): 87-97. doi: $10.1111 /$ nure. 12129

Bipasha M, Raisa T, Goon S. 2017. Sugar sweetened beverages consumption among university students of Bangladesh. International Journal of Public Health Science, doi: http://doi.org/10.11591/ijphs.v6i2.6635

Bjorksten O, Sutherland S, Miller C, Stewart T. 1983. Identification of medical student problems and comparisons with those of other students. Journal of Medical Education. 58: 759-767

Champlin SE, Pasch KE, Perry CL. 2016. Is the Consumption of Energy Drinks Associated with Academic Achievement Among College Students? The Journal of Primary Prevention. 37(4): 345-359. doi: 10.1007/s10935-016-0437-4 
Chatterjee P, Chandra S, Dey P, Bhattacharya S. 2012. Evaluation of anti-inflammatory effects of green tea and black tea: a comparative in vitro study. Journal of Advanced Pharmaceuticals Technology and Research. 3: 136. doi: 10.4103/2231-4040.97298

Hicks MB, Hsieh YP, Bell LN. 1996. Tea preparation and its influence on methylxanthine concentration. Food research international. 29(3-4): 325-330

Hodgson JM, Croft KD. 2010. Tea flavonoids and cardiovascular health. Molecular Aspects of Medicine. 31: 495-502. doi: 10.1016/j.mam.2010.09.004

Lambert DJ, Vernarelli AJ. 2013. Tea consumption is inversely associated with weight status and other markers for Metabolic Syndrome in U.S. adults. European journal of nutrition. 52(3): 1039-1048. doi: 10.1007/s00394-012-0410-9

Majori S, Pilati S, Gazzani D, Paiano J, Ferrari S. 2018. Energy drink and ginseng consumption by Italian university students: a cross-sectional study. Journal of Preventive Medicine and Hygiene. 59(1): E63-E74. doi: 10.15167/24214248/jpmh2018.59.1.813

Martins A, Ferreira C, Sousa D, Costa S. 2018. Consumption Patterns of Energy Drinks in Portuguese Adolescents from A City in Northern Portugal. Acta Médica Portuguesa. 31(4): 207-212. doi: 10.20344/amp.9403

McIlvain GE, Noland MP, Bickel R. 2011. Caffeine consumption patterns and beliefs of college freshmen. American Journal of Health Education. 42(4): 235-244, doi: https://doi.org/10.1080/19325037.2011.10599193

Nowak D, Gośliński M, Nowatkowska K. 2018. The effect of acute consumption of energy drinks on blood pressure, heart rate and blood glucose in the group of young adults. International Journal of Environmental Research and Public Health. 15(3): 544. doi: 10.3390/ijerph15030544
Nowak D, Jasionowski A. 2015. Analysis of the Consumption of Caffeinated Energy Drinks among Polish Adolescents. International Journal of Environmental Research and Public Health. 12: 10-21. doi: 10.3390/ijerph120707910

Naveed S, Hameed A. 2014. Consumption of Tea in Professionals and Non-professionals. SOJ Pharm Pharm Sci, doi: http://dx.doi.org/10.15226/2374-6866/1/3/00116

Subramaniam P, Eswara U, Maheshwar RKR. 2012. Effect of different types of tea on Streptococcus mutans: an in vitro study. Indian Journal of Dental Research. 23: 43

Shimbo M, Nakamura K, Shi HJ, Kizuki M, Seino K, Inose T, Takano T. 2005. Green tea consumption in everyday life and mental health. Public health nutrition. 8(8): 1300-1306. doi: $10.1079 / \mathrm{phn} 2005752$

The Daily Star 2019. Tea production surges on favourable weather. Available from: https://www.thedailystar.net/business/news/ tea-production-surges-favourable-weather-1812154 [Accessed 5 August 2020]

Vartanian LR, Schwartz MB, Brownell KD. 2007. Effects of soft drink consumption on nutrition and health: a systematic review and meta-analysis. American Journal of Public Health. 97: 667-675. doi: 10.2105/AJPH.2005.083782

Wu CH, Lu FH, Chang CS, Chang TC, Wang RH, Chang CJ. 2003. Relationship among habitual tea consumption, percent body fat, and body fat distribution. Journal of Obesity Research. 11: 1088-1095. doi: 10.1038/oby.2003.149

Xiong C, Liu C, Pan W, Ma F, Xiong C, Qi L, Chen F, Lu X, Yang J, Zheng L. 2015. Non-destructive determination of total polyphenols content and classification of storage periods of Iron Buddha tea using multispectral imaging system. Journal of Food Chemistry. 176: 130-136. doi: 10.1016/j.foodchem.2014.12.057 